\title{
Wihania somnifera extract as a friendly corrosion inhibitor of carbon steel in $\mathrm{HCl}$ solution
}

\author{
A.S. Fouda, ${ }^{1}$ * * A.M. Ahmed, ${ }^{2}$ S.M. El-Darier ${ }^{2}$ and I.M. Ibrahim ${ }^{2}$ \\ ${ }^{1}$ Chemistry Department, Faculty of Science, El-Mansoura University, Mansoura, Egypt \\ ${ }^{2}$ Chemistry Department, Faculty of Science, Alexandria University, Egypt \\ *E-mail: asfouda@hotmail.com
}

\begin{abstract}
There are many methods used to control the dissolution of metals. The use of inhibitors is one of such processes. Once chromates and some organic compounds were used as corrosion inhibitors. However, environmental scientists do not encourage this because chromates and those organic derivatives are toxic in nature. So, researchers are looking for environmentally friendly corrosion inhibitors such as extracts of plant materials. Several plant materials have been used for this purpose. Wihania somnifera (WSE) was studied as a friendly corrosion inhibitor against carbon steel corrosion in $1 \mathrm{M}$ hydrochloric acid by mass reduction (MR), potentiodynamic polarization (PP), electrochemical frequency modulation (EFM) and electrochemical impedance spectroscopy (EIS) techniques. Surface analysis was performed on carbon steel with and without Wihania somnifera using an atomic force microscope (AFM). The impact of temperature was studied and explained. Investigation of experimental data denote that the inhibition efficiency (IE\%) raises with raising concentration of Wihania somnifera extract while decreases with raising temperature. The activation and adsorption thermodynamic parameters such as $\Delta S^{*}, \Delta H^{*}$ and $E_{\mathrm{a}}^{*}$ were calculated and explained. The negative sign of $\Delta G^{0}$ indicates that the process is spontaneous. Potentiodynamic polarization data identified that this Wihania somnifera extract acts as a mixed inhibitor and is physically adsorbed on carbon steel surface following the Langmuir adsorption isotherm. The charge transfer resistance increases, while the double layer capacitance decreases with an increase in Wihania somnifera extract concentration. The data from various techniques are in good agreement.
\end{abstract}

Keywords: corrosion inhibition, Wihania somnifera extract, carbon steel, HCl, EIS, mass reduction, potentiodynamic polarization.

Received: October 05, 2020. Published: February 19, 2021

doi: $\underline{10.17675 / 2305-6894-2021-10-1-14}$

\section{Introduction}

Carbon steels (CS) have wide application in industry and in our everyday lives due to their amazing properties, and moreover, it is the foremost ubiquity sort of steel alloys utilized in many industrial communities. Carbon steel is considered the foundation for the larger part of business and finds worldwide utilization in tremendous amounts. Every year petrochemical plants, oil and gas generation utilize colossal amounts of CS $[1,2]$. One disadvantage of carbon steel is that it is readily damaged in humidity and corrosive media. 
In order to remove rust and other corrosion products, pickling operations are performed utilizing strong acids [3-6]. Corrosion mitigation of CS in direct contact or completely immersed in a corrosive medium can be done effectively by many corrosion inhibitors. One of the methods to protect metals and alloys from corrosion is by the use of inhibitors. Numerous researches demonstrated that increasing inhibitor concentrations and decreasing the concentration of an acid reduce the undesired metal disintegration, i.e., control the damaging impact of corrosion [7-12].

The aim of this paper is the use of environmentally friendly materials as inhibitors for CS corrosion in $1 \mathrm{M} \mathrm{HCl}$ solution, and the choice was to use Wihania somnifera to protect CS from corrosion. The use of plant extracts was chosen due to their cheapness and availability. In this research, several methods were utilized to examine the protective behavior, including electrochemical and chemical studies, as well as analysis of the metal surface by different techniques.

\section{Experimental}

\section{Materials and solutions}

Table 1 shows chemical composition of the utilized CS.

Table 1. Chemical composition (weight \%) of CS specimens.

\begin{tabular}{ccccccc}
\hline Element & $\mathbf{C}$ & $\mathbf{M n}$ & $\mathbf{P}$ & $\mathbf{S}$ & $\mathbf{S i}$ & $\mathbf{F e}$ \\
\hline$\%$ wt. & 0.2000 & 0.3500 & 0.0390 & 0.040 & 0.360 & 99.0110 \\
\hline
\end{tabular}

\section{Preparation of plant extract (Wihania somnifera)}

Wihania somnifera were gathered, dried in an oven at $70^{\circ} \mathrm{C}$ for 6 hours, then crushed. 50 grams of the Wihania somnifera powder was refluxed in $500 \mathrm{ml}$ bidistilled water for one hour. The aqueous solution was filtered and concentrated to $100 \mathrm{ml}$. This solution was utilized to prepare solutions with various concentrations by dilution.

\section{Chemical measurement (Mass reduction, MR)}

Carbon steel specimens with identical geometrical dimensions $(2 \times 2 \times 0.2 \mathrm{~cm})$ were weighed before dipping in $100 \mathrm{ml}$ of $\mathrm{HCl}$ solutions in the presence and absence of various concentrations of Wihania somnifera extract. All the corrosive environments were exposed to air. The tests were performed in $1 \mathrm{M} \mathrm{HCl}$ to compare with a sample that was placed in a solution of $1 \mathrm{M}$ hydrochloric acid with various concentrations of Wihania somnifera extract. Samples were left for half an hour in solutions, then collected and dried. The samples are weighed and then placed again in the same solutions. The steps were repeated every half an hour until the end of the experiment after 2.5 hours [13]. The $k_{\text {corr }}$ (corrosion rate) of the CS sample were computed utilizing the following relationship: 


$$
k_{\text {corr }}=\frac{\Delta W}{A t}
$$

where $\Delta \mathrm{W}$ is the mass reduction, $\mathrm{A}$ is the sample surface area exposed to the solution in $\mathrm{cm}^{2}$, and $\mathrm{t}$ in min is the immersion time. The average MR was measured and $I E \%$ and the degree of surface coverage $(\theta)$ were calculated from the equation:

$$
I E \%=100 \cdot \theta=\left[1-\frac{W}{W^{0}}\right] \cdot 100
$$

where $W^{0}$ and $W$ are the MR data of CS in $1 \mathrm{M} \mathrm{HCl}$ (blank) and in solutions inhibited by Wihania somnifera extract, correspondingly.

\section{Electrochemical techniques}

Electrochemical tests were performed in a cell involving three classic electrodes, one of which was the CS working electrode that was studied. Prior to each experiment, the surface of CS coins was mechanically polished with altering grades of emery papers and rinsed by bidistilled water. The exposed surface area was $1 \mathrm{~cm}^{2}$. The second electrode was the reference electrode and the third electrode was the auxiliary electrode [14]. The working electrode was placed for 30 minutes in the solution used at the open circuit potential, where a stable state was reached.

\section{Electrochemical frequency modulation (EFM) measurements}

Two frequencies, namely 2 and $5 \mathrm{~Hz}$, were used for potential perturbation, while a frequency of $0.1 \mathrm{~Hz}$ was used in the EFM test. The CF-2 and CF-3 causality factors, $I_{\text {corr }}, \beta_{\mathrm{a}}$ and $\beta_{\mathrm{c}}$ were calculated by using the largest peeks $[15,16]$.

\section{Electrochemical impedance (EIS) measurements}

The open circuit potential (OCP) was used and current signals were measured in frequency range from $100 \mathrm{kHz}$ to $10 \mathrm{~Hz}$ for impedance measurements [17]. The $\theta$ and $I E \%$ were determined by the following Equation 3:

$$
I E \%=100 \cdot\left[1-\frac{R_{\mathrm{ct}(\mathrm{free})}}{R_{\mathrm{ct}(\mathrm{inh})}}\right]
$$

Where $R_{\mathrm{ct}(\text { free) }}$ and $R_{\mathrm{ct}(\mathrm{inh})}$ are the resistances with and without Wihania somnifera extract, respectively.

Potentiodynamic polarization (PP) tests

The PP scan was used to record Tafel curves by sweeping the working potential from -700 to $700 \mathrm{mV}$ at a scan rate of $0.5 \mathrm{mV} \mathrm{s}^{-1}$. $I_{\text {corr }}$ was calculated by extrapolation of cathodic and 
anodic Tafel lines to give $\log I_{\text {corr }}$ and $E_{\text {corr }} \theta$ and $I E \%$ were derived from the EIS results using the Equation 4 below.

$$
E \%=100 \cdot\left[1-\frac{I_{\text {corr(inh) }}}{I_{\text {corr(free) }}}\right]=\theta \cdot 100
$$

where $I_{\text {corr(inh) }}$ and $I_{\text {corrfree) }}$ are the corrosion currents in the presence and absence of Wihania somnifera extract, correspondingly.

Surface Analysis

Atomic force microscopy (AFM) test

This technique provides a $3 \mathrm{~d}$ dimensional picture of the CS corroded surface and gives information about the corrosion process. This can be done by using a Pico SPP2100 AFM device that provides the roughness of the surface that can be evidence of the inhibition of Wihania somnifera on a CS surface.

Fourier transform infrared (FTIR) test

Thermo Fisher Scientific, Waltham, MA, USA was used to record FT-IR spectra that give us information about the inhibitor structure based on peaks corresponding to the functional groups of chemical compounds in the Wihania somnifera inhibitor.

\section{Results and Discussion}

Mass reduction (MR) test

Data on corrosion rate, $\theta$ and $I E \%$ of carbon steel in $1 \mathrm{M} \mathrm{HCl}$ solution with various concentrations of Wihania somnifera extract are given in Table 2. The MR of carbon steel in the acid environment with and without various concentrations of Wihania somnifera extract after various immersion times $(30-150 \mathrm{~min})$ at $25^{\circ} \mathrm{C}$ are given in Figure 1 . The $I E \%$ improved with an increase in the concentration of the Wihania somnifera extract. The inhibition is due to the adsorption of Wihania somnifera extract on the carbon steel and formation of a layer from adsorbed Wihania somnifera molecules on carbon steel surface which separates the carbon steel surface from the acid solution and blocks the corrosion sites [18-20].

\section{Adsorption isotherms}

Wihania somnifera extract is adsorbed on the CS surface because the energy of interaction between the CS surface and the extract is larger than that between $\mathrm{H}_{2} \mathrm{O}$ molecules and the metal [21]. The Langmuir adsorption isotherm fits the data obtained perfectly (Figure 2). The Langmuir adsorption isotherm is expressed as: 


$$
\frac{C}{\theta}=\frac{1}{K_{\text {ads }}}+C
$$

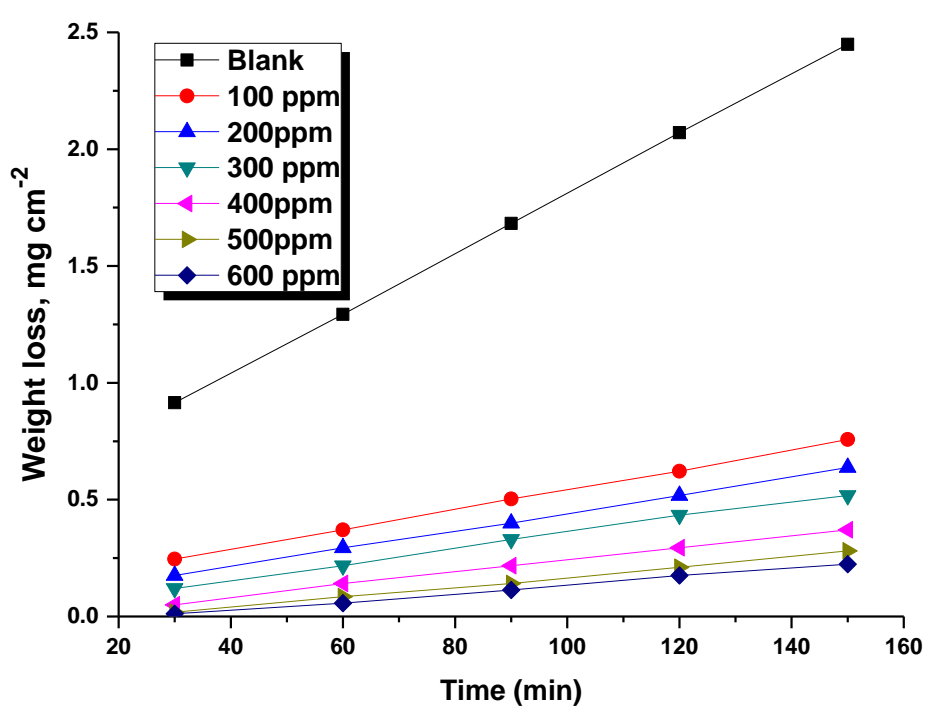

Figure 1. MR-time plots for CS corrosion with and without various concentrations of Wihania somnifera extract.

Table 2. Influence of various concentrations of Wihania somnifera extract on $k_{\mathrm{corr}}\left(\mathrm{mg} \times \mathrm{cm}^{-2} \times \mathrm{min}^{-1}\right)$ and $I E \%$ of $\mathrm{CS}$ in $1 \mathrm{M} \mathrm{HCl}$ at various temperatures.

\begin{tabular}{|c|c|c|c|c|c|c|c|c|c|c|}
\hline \multirow[t]{2}{*}{$\begin{array}{l}\text { Conc. } \\
\text { ppm }\end{array}$} & \multicolumn{2}{|c|}{$25^{\circ} \mathrm{C}$} & \multicolumn{2}{|c|}{$30^{\circ} \mathrm{C}$} & \multicolumn{2}{|c|}{$35^{\circ} \mathrm{C}$} & \multicolumn{2}{|c|}{$40^{\circ} \mathrm{C}$} & \multicolumn{2}{|c|}{$45^{\circ} \mathrm{C}$} \\
\hline & $k_{\text {corr }}$ & $I E \%$ & $k_{\text {corr }}$ & $I E \%$ & $k_{\text {corr }}$ & IE\% & $k_{\text {corr }}$ & IE\% & $k_{\text {corr }}$ & IE\% \\
\hline Blank & 0.116 & - & 0.014 & - & 0.192 & - & 0.419 & - & 0.513 & - \\
\hline 100 & 0.034 & 70.7 & 0.047 & 66.5 & 0.068 & 64.3 & 0.1609 & 61.6 & 0.2098 & 59.1 \\
\hline 200 & 0.023 & 79.9 & 0.045 & 68 & 0.064 & 66.6 & 0.1496 & 64.3 & 0.1975 & 61.5 \\
\hline 300 & 0.018 & 84.1 & 0.038 & 72.7 & 0.055 & 71.3 & 0.1307 & 68.8 & 0.172 & 66.3 \\
\hline 400 & 0.014 & 87.6 & 0.030 & 78.5 & 0.046 & 76 & 0.1110 & 73.5 & 0.1488 & 71 \\
\hline 500 & 0.012 & 89.5 & 0.025 & 82.2 & 0.037 & 80.4 & 0.088 & 78.8 & 0.1185 & 76.9 \\
\hline 600 & 0.010 & 91.3 & 0.020 & 85.3 & 0.031 & 83.6 & 0.0758 & 81.9 & 0.1067 & 79.2 \\
\hline
\end{tabular}

The plot of $C$ vs. $C / \theta$ of Wihania somnifera at various temperatures is shown in Figure 2. This plot gives straight lines with an intercept equals to $1 / K_{\text {ads. }}$ The change in the free energy of adsorption ( $\Delta G_{\text {ads }}^{0}$ ) was determined from the following relation:

$$
\Delta G_{\mathrm{ads}}^{0}=-R T \ln \left(55.5 K_{\mathrm{ads}}\right)
$$


The $\Delta G_{\text {ads }}^{0}$ values at all temperatures are reported in Table 3. The changes in adsorption enthalpy $\left(\Delta H_{\mathrm{ads}}^{0}\right)$ were determined from the following equation:

$$
\log K_{\mathrm{ads}}=\left(\frac{-\Delta H_{\mathrm{ads}}^{0}}{2.303 R T}\right)+\text { constant }
$$

The plot of $\log K_{\mathrm{ads}}$ vs. $1 / \mathrm{T}$ is shown in Figure 3. The slope of the line is ( $\left.-\Delta H_{\text {ads }}^{0} / 2.303 \mathrm{R}\right)$, the $\Delta H_{\text {ads }}^{0}$ data were reported in Table 3. Then the following equation (7):

$$
\Delta G_{\mathrm{ads}}^{0}=\Delta H_{\mathrm{ads}}^{0}-T \Delta S_{\mathrm{ads}}^{0}
$$

was used to obtain $\Delta S_{\text {ads }}^{0}$ at various temperatures. Table 3 shows the adsorption parameters obtained for the Wihania somnifera extract. The negative $\Delta G_{\text {ads }}^{0}$ values obtained confirm the spontaneous adsorption of Wihania somnifera on the CS surface. The values of $\Delta G_{\text {ads }}^{0}$ smaller than $-20 \mathrm{~kJ} / \mathrm{mol}$ indicate that physical adsorption is observed [22]. The $\Delta H_{\text {ads }}^{0}$ value is negative, which means that adsorption of Wihania somnifera is exothermic. The fact that the $\Delta H_{\mathrm{ads}}^{0}$ value is less than $40 \mathrm{~kJ} / \mathrm{mol}$ refers to a physisorption process. The positive $\Delta S_{\mathrm{ads}}^{0}$ value obtained is due to an increase in disorder due to desorption of water molecules from the CS surface $[23,24]$.

Table 3. Langmuir adsorption parameters of Wihania somnifera extract on the CS surface at various temperatures.

\begin{tabular}{ccccc}
\hline Temp., $\boldsymbol{K}$ & $\boldsymbol{K}_{\text {ads }}, \mathbf{M}^{-\mathbf{1}}$ & $-\Delta \boldsymbol{G}_{\text {ads }}^{\mathbf{0}}, \mathbf{k J} \cdot \mathbf{m o l}^{-\mathbf{1}}$ & $-\Delta \boldsymbol{H}_{\text {ads }}^{\mathbf{0}}, \mathbf{k J} \cdot \mathbf{m o l} \mathbf{l}^{\mathbf{1}}$ & $\begin{array}{c}-\Delta \boldsymbol{S}_{\text {ads }}^{\mathbf{0}}, \\
\mathbf{J} \cdot \mathbf{m o l}^{\mathbf{- 1}} \cdot \mathbf{K}^{\mathbf{- 1}}\end{array}$ \\
\hline 298 & 67 & 20.5 & 67.1 \\
303 & 62 & 20.1 & & 66.4 \\
308 & 59 & 19.5 & 28.3 & 63.4 \\
313 & 52 & 19.3 & & 62.6 \\
318 & 49 & 18.2 & 60.3 \\
\hline
\end{tabular}

\section{Thermodynamic parameters}

The activation energy $\left(E_{\mathrm{a}}^{*}\right)$ for dissolution of the CS was determined from the slope of log $k_{\text {corr }}$ versus $1 / T$ drawn by applying Arrhenius equation (7) (Figure 4):

$$
k_{\text {corr }}=A \cdot \exp \left(-\frac{E_{\mathrm{a}}^{*}}{R T}\right)
$$


Where $A$ is the Arrhenius pre-exponential factor. $E_{\mathrm{a}}^{*}$ increases in the presence of Wihania somnifera extract.

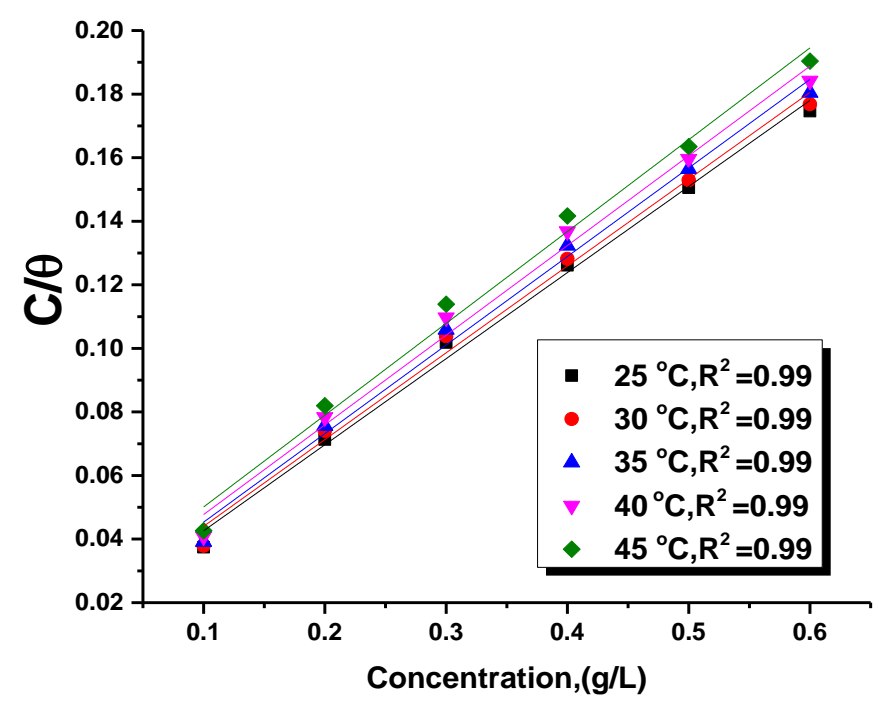

Figure 2. Langmuir plots of Wihania somnifera extract on CS surface in $1 \mathrm{M} \mathrm{HCl}$ at various temperatures.

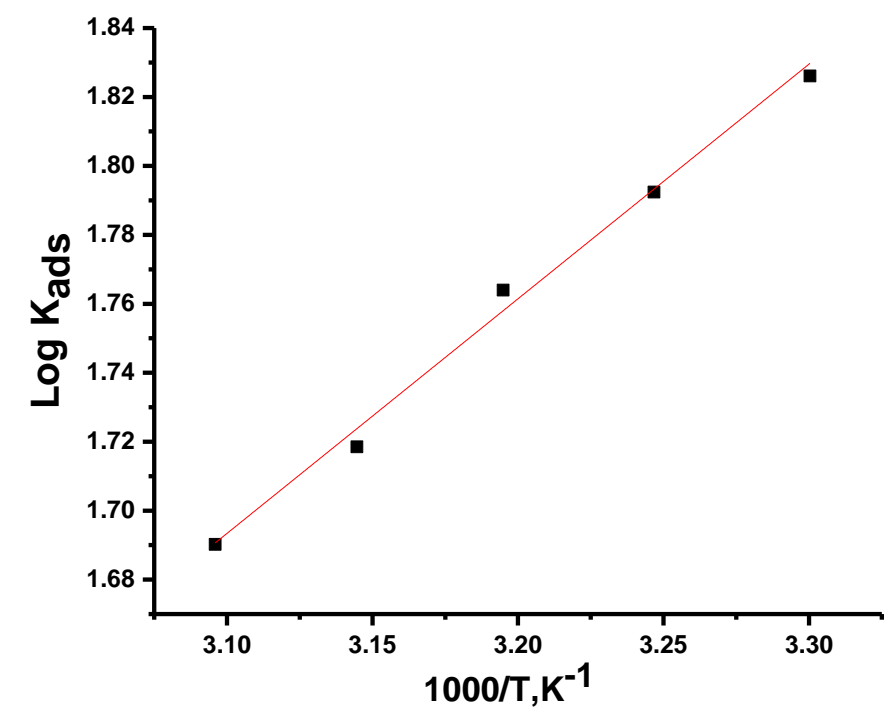

Figure 3. $\left(\log \left(K_{\text {ads }}\right)\right)$ vs. $(1 / T)$ for the dissolution of CS in $1 \mathrm{M} \mathrm{HCl}$ at various temperatures.

The results shown in Table 4 indicate that the activation energy increases with an increase in Wihania somnifera concentration due to an increase in the thickness of the barrier layer formed on the CS surface. This increase is due to the adsorption of Wihania somnifera extract on the CS surface and corresponds to physical adsorption [25]. The transitional state equation relates the changes in entropy and enthalpy as follows: 


$$
k_{\text {corr }}=\left(\frac{R T}{N h}\right) \cdot \exp \left(\frac{\Delta S^{*}}{R}\right) \cdot \exp \left(\frac{-\Delta H^{*}}{R T}\right)
$$

Where $h$ is the Planck constant. Figure 5, shows straight lines resulting from the plot of log $\left(k_{\mathrm{corr}} / T\right)$ against $1000 / T$, and this figure shows the transitional state of the Wihania somnifera. The slopes of the curves were utilized to calculate the enthalpy $\left(-\Delta H^{*} / 2.303 R\right)$, and $\Delta S^{*}$ was obtained from the intercept of the lines. $\Delta S^{*}$ data are negative in the presence of Wihania somnifera. These negative data demonstrate that the activated complex in the rate determining step favors coagulation rather than separate molecules in solution, so the lowering in disorder occurred throughout the sequence from the reactant to the starting complex [26, 27].

Table 4. Thermodynamic parameters for dissolution of CS with and without various concentrations of Wihania somnifera extract.

\begin{tabular}{|c|c|c|c|}
\hline Conc., ppm & $E_{\mathrm{a}}^{*}, \mathrm{~kJ} \cdot \mathrm{mol}^{-1}$ & $\Delta H^{*}, \mathbf{k J} \cdot \mathbf{m o l}^{-1}$ & $-\Delta S^{*}, \mathbf{J} \cdot \mathbf{m o l}^{-1} \cdot \mathbf{K}^{-1}$ \\
\hline 0 & 64.9 & 62.2 & 88.3 \\
\hline 100 & 74.1 & 71.4 & 85.3 \\
\hline 200 & 75.3 & 72.6 & 65.1 \\
\hline 300 & 75.4 & 72.7 & 64.0 \\
\hline 400 & 76.7 & 74.0 & 62.7 \\
\hline 500 & 77.3 & 74.6 & 62.0 \\
\hline 600 & 79.5 & 76.8 & 61.7 \\
\hline
\end{tabular}

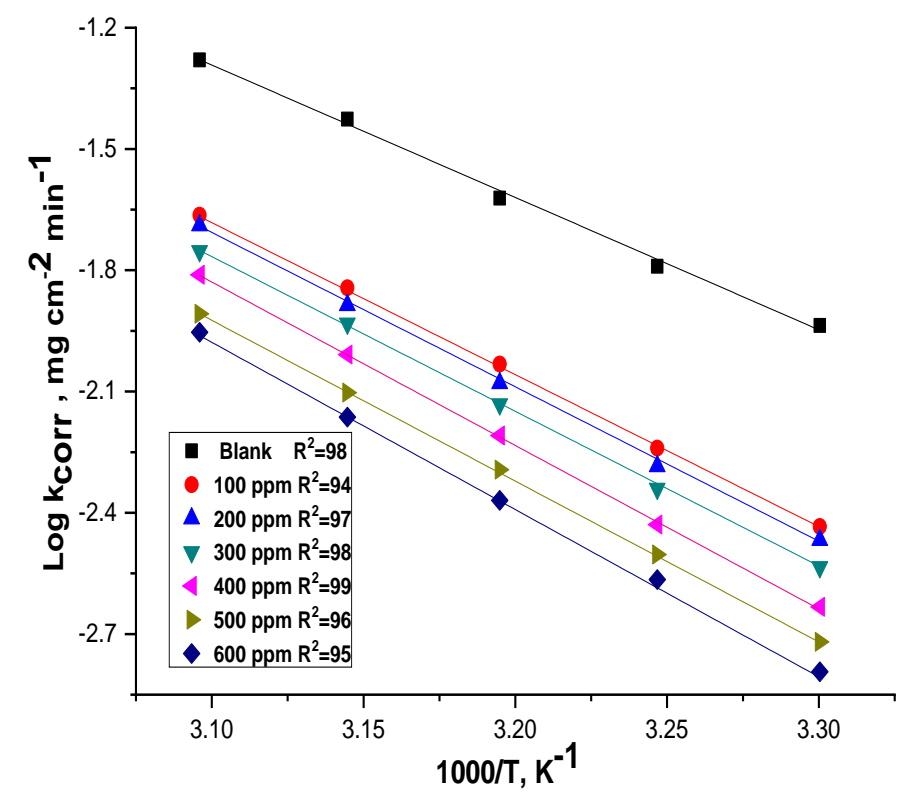

Figure 4. $\log k_{\text {corr }} v s .1 / T$ curves for CS corrosion with and without various concentrations of Wihania somnifera extract. 


\section{PP measurements}

$\mathrm{PP}$ plots for CS with various concentrations of Wihania somnifera extract at $25^{\circ} \mathrm{C}$ are shown in Figure 6. From the Figure, one can note that both cathodic (hydrogen discharge) and anodic reactions (carbon steel dissolution) were inhibited by addition of various concentrations of Wihania somnifera extract. Both $\beta_{\mathrm{a}}$ and $\beta_{\mathrm{c}}$ changed in the positive and negative directions, respectively. The electrochemical parameters $E_{\text {corr }}, \beta_{\mathrm{a}}$ and $\beta_{\mathrm{c}}, \theta, I E \%$ and $i_{\text {corr }}$ were measured and given in Table 5. Data showed that on addition of the extract, the $i_{\text {corr }}$ values decreased while the values of $E_{\text {corr }}$ (max. shift $18 \mathrm{mV}$ ), $\beta_{\mathrm{a}}$, and $\beta_{\mathrm{c}}$ did not change significantly. This indicates that Wihania somnifera extract acts as a mixed kind inhibitor [28]. The Tafel lines are almost parallel, which indicates that there is no change in the cathodic hydrogen evolution mechanism and metal dissolution mechanism.

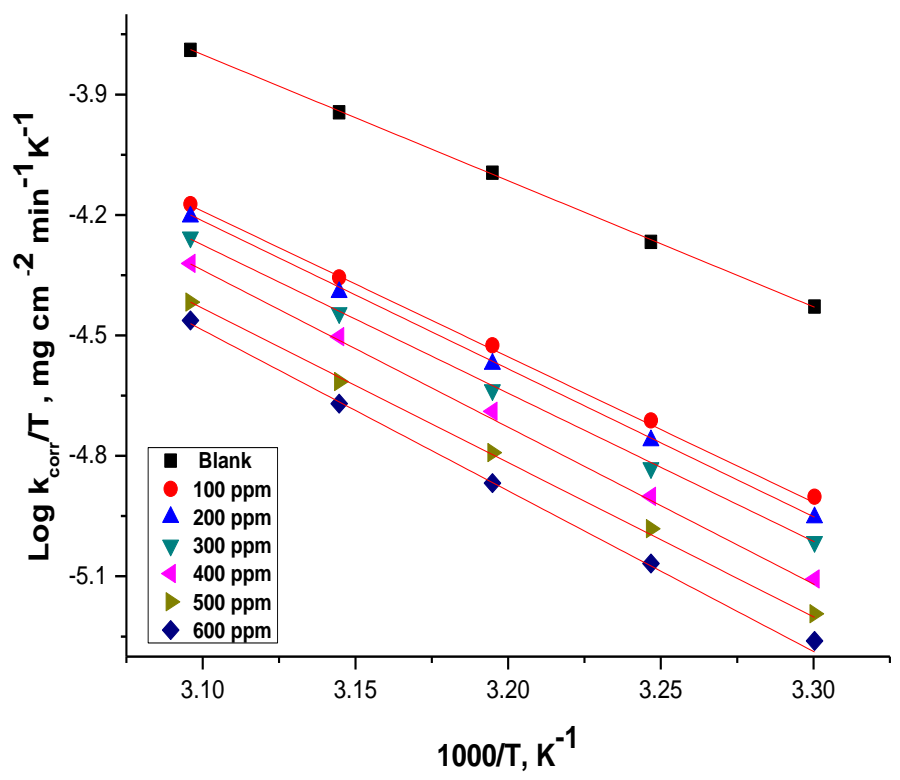

Figure 5. Log $\left(k_{\text {corr }} / T\right)$ vs. $1 / T$ plots for CS corrosion with and without various concentrations of Wihania somnifera extract.

Table 5. Electrochemical parameters, $i_{\text {corr }}, E_{\text {corr, }} \beta_{\mathrm{a}}, \beta_{\mathrm{c}}, k_{\mathrm{corr}}, \theta$ and $I E \%$ of CS corrosion with and without various concentrations of Wihania somnifera extract at $25^{\circ} \mathrm{C}$

\begin{tabular}{cccccccc}
\hline $\begin{array}{c}\text { Conc. } \\
(\mathbf{p p m})\end{array}$ & $\begin{array}{c}\boldsymbol{i}_{\text {corr. }} \\
\boldsymbol{\mu A} \cdot \mathbf{c m}^{-\mathbf{2}}\end{array}$ & $\begin{array}{c}-\boldsymbol{E}_{\text {corr. }} \\
\mathbf{m V}(\mathbf{S C E})\end{array}$ & $\begin{array}{c}\boldsymbol{\beta}_{\mathbf{a}} \\
\mathbf{m V} \mathbf{d e c}^{-\mathbf{1}}\end{array}$ & $\begin{array}{c}-\boldsymbol{\beta}_{\mathbf{c}} \\
\mathbf{m V} \mathbf{d e c}^{-\mathbf{1}}\end{array}$ & $\begin{array}{c}\mathbf{C .} \mathbf{R} . \\
\mathbf{m p y}\end{array}$ & $\boldsymbol{\theta}$ & $\boldsymbol{I E \%}$ \\
\hline $\mathbf{0}$ & 2530 & 461 & 124 & 168 & 138 & - & - \\
$\mathbf{1 0 0}$ & 1016 & 462 & 115 & 152 & 11.9 & 0.598 & 59.8 \\
$\mathbf{2 0 0}$ & 808 & 466 & 121 & 159 & 10.5 & 0.681 & 68.1 \\
$\mathbf{3 0 0}$ & 693 & 471 & 122 & 142 & 5.6 & 0.726 & 72.6 \\
$\mathbf{4 0 0}$ & 568 & 476 & 114 & 141 & 4.9 & 0.775 & 77.5 \\
$\mathbf{5 0 0}$ & 448 & 479 & 115 & 139 & 4.4 & 0.823 & 82.3 \\
$\mathbf{6 0 0}$ & 372 & 483 & 118 & 148 & 3.8 & 0.853 & 85.3 \\
\hline
\end{tabular}




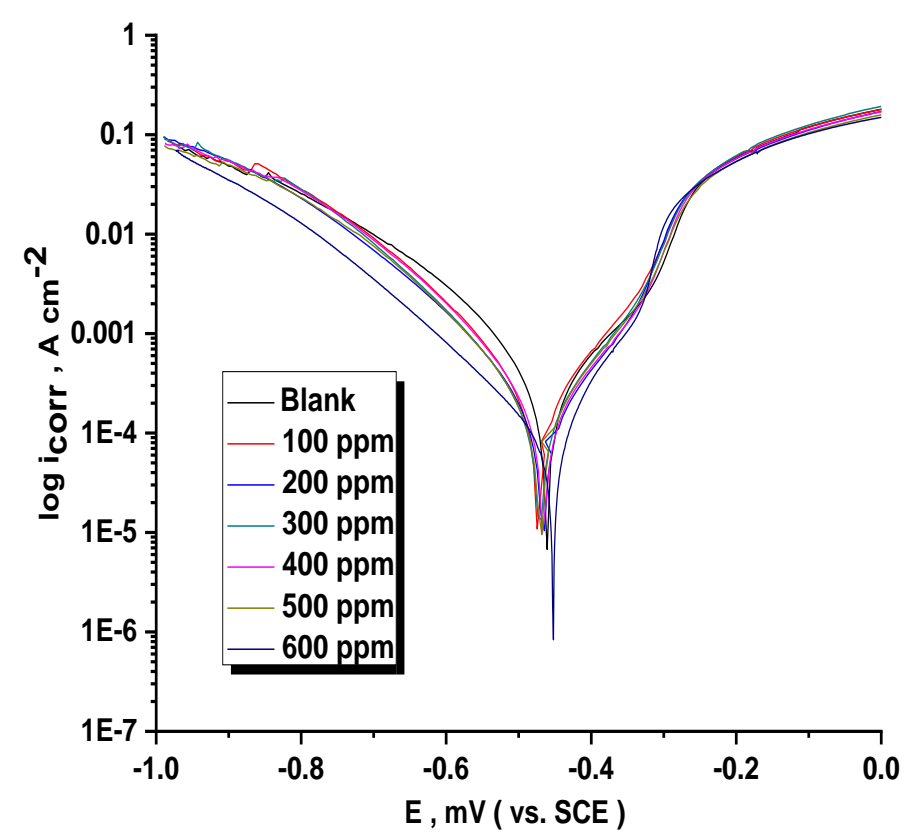

Figure 5. PP diagram for CS corrosion with and without various concentrations of Wihania somnifera extract at $25^{\circ} \mathrm{C}$.

\section{EFM Tests}

The data obtained from EFM for $\mathrm{CS}$ in $1 \mathrm{M} \mathrm{HCl}$ at various concentrations of Wihania somnifera extract at $25^{\circ} \mathrm{C}$ were measured and are listed in Table 6 . The results indicate that $i_{\text {corr }}$ decreases with an increase in the concentration of Wihania somnifera extract while IE\% increases. This indicates that this extract is an inhibitor of CS in acid medium. The CF are similar to their theoretical values (2\&3). This indicates the validity of the results obtained. The values of $i_{\text {corr }}$ can be obtained directly from EFM measurements and independent of the knowledge of Tafel constants. The IE\% can be calculated as in Equation 3.

Table 6. EFM technique for CS corrosion in the presence and absence of various concentrations of Wihania somnifera extract at $25^{\circ} \mathrm{C}$.

\begin{tabular}{|c|c|c|c|c|c|c|c|c|}
\hline $\begin{array}{l}\text { Conc. } \\
\text { (ppm) }\end{array}$ & $\begin{array}{c}i_{\text {corr }} \\
\mu \mathrm{A} \mathrm{cm}^{-2}\end{array}$ & $\begin{array}{c}\beta_{\mathrm{a}} \\
\mathrm{mV} \operatorname{dec}^{-1}\end{array}$ & $\begin{array}{c}\beta_{\mathrm{c}} \\
\mathrm{mV} \operatorname{dec}^{-1}\end{array}$ & CF-2 & CF-3 & $\begin{array}{l}k_{\text {corr }} \\
\text { mpy }\end{array}$ & $\theta$ & $I E \%$ \\
\hline Blank & 4763 & 100 & 120 & 2.2 & 3.0 & 118 & - & - \\
\hline 100 & 1253 & 96 & 110 & 2.0 & 3.3 & 79 & 0.737 & 73.7 \\
\hline 200 & 972 & 90 & 118 & 1.9 & 3.0 & 73 & 0.796 & 79.6 \\
\hline 300 & 867 & 92 & 109 & 2.0 & 3.2 & 68 & 0.818 & 81.8 \\
\hline 400 & 710 & 90 & 110 & 1.9 & 2.9 & 53 & 0.851 & 85.1 \\
\hline 500 & 576 & 91 & 115 & 2.2 & 3.2 & 49 & 0.879 & 87.9 \\
\hline 600 & 472 & 88 & 118 & 1.9 & 2.8 & 32 & 0.901 & 90.1 \\
\hline
\end{tabular}




\section{EIS measurements}

The EIS of CS at the various concentrations of Wihania somnifera extract are shown in Figure 7a-b where Figure 7a shows the Nyquist plots and Figure 7b, the Bode plots. The curves show that the each semicircle of the Nyquist plots gradually increases with an increase in the concentration of Wihania somnifera extract. The EIS parameters obtained, $R_{\mathrm{ct}}$, the double layer capacitance $C_{\mathrm{dl}}$, and $I E \%$ are listed in Table 7 . These data showed that there is an increase in $R_{\mathrm{ct}}$ and a decrease in $C_{\mathrm{dl}}$. From all the above, a high resistance is established due to adsorption of the Wihania somnifera extract at the CS-solution interface. The equivalent circuit that fits the EIS data is presented in Figure 8. The results showed a decrease in the $C_{\mathrm{dl}}$ values with an increase in the concentration of Wihania somnifera, and this can be explained by a decrease in the local dielectric constant and/or an increase in the thickness of the double electrical layer. This is due to the adsorption of Wihania somnifera molecules on the CS/solution interface.
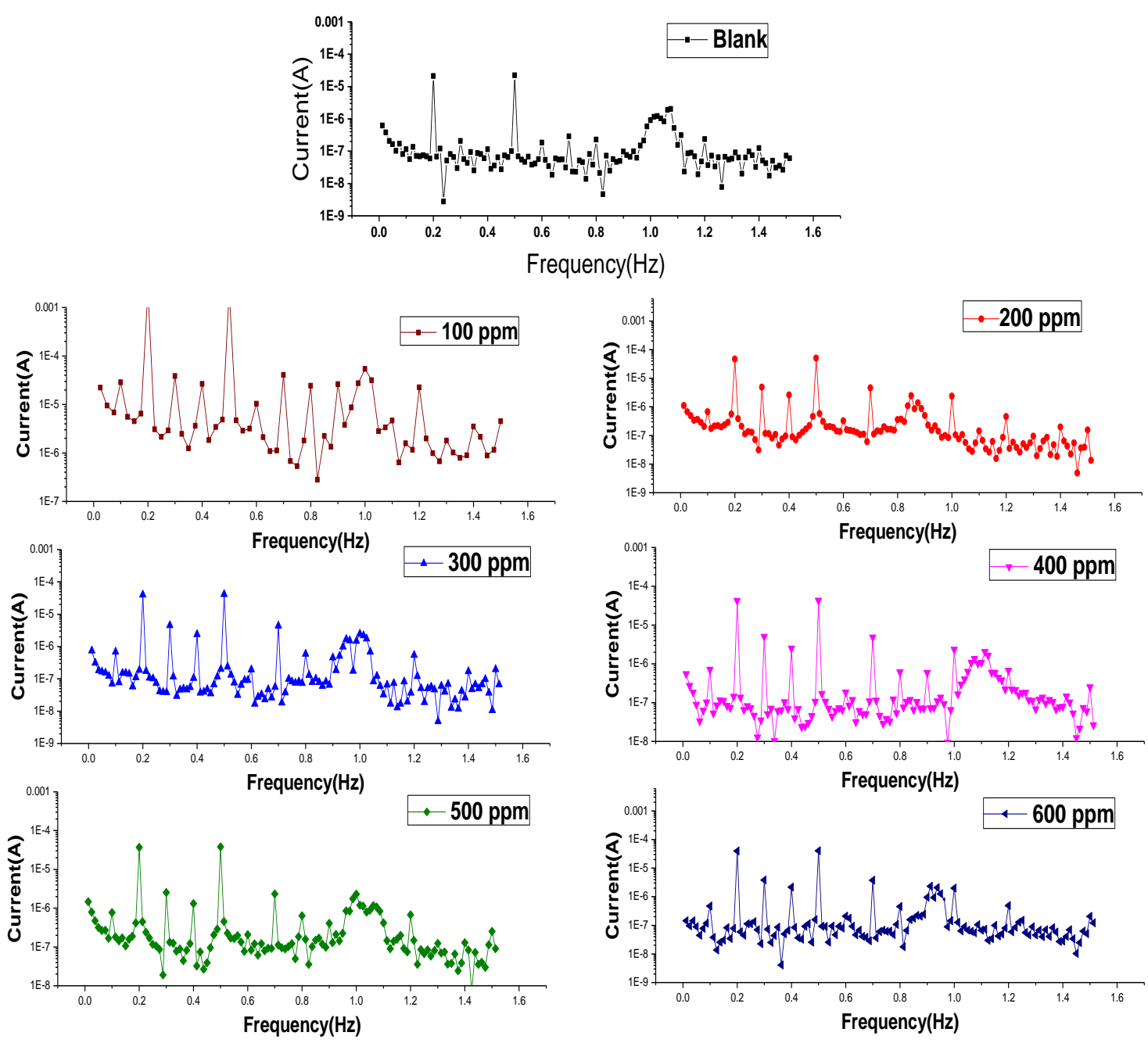

Figure 6. Intermodulation spectrum for CS corrosion with and without various concentrations of Wihania somnifera extract at $25^{\circ} \mathrm{C}$. 
Table 7. Data from EIS measurements for CS dissolution with and without various concentrations of Wihania somnifera extract at $25^{\circ} \mathrm{C}$.

\begin{tabular}{ccccc}
\hline $\begin{array}{c}\text { Conc., } \\
\mathbf{p p m}\end{array}$ & $\begin{array}{c}\boldsymbol{R}_{\mathrm{ct}}, \\
\mathbf{\Omega ~ c m}^{\mathbf{2}}\end{array}$ & $\begin{array}{c}\boldsymbol{C}_{\mathbf{d l},} \\
\boldsymbol{\mu} \mathbf{~ \mathbf { ~ m } ^ { - 2 }}\end{array}$ & $\boldsymbol{\theta}$ & $\boldsymbol{I E \%}$ \\
\hline Blank & 25 & 385 & - & - \\
100 & 98 & 150 & 0.745 & 74.5 \\
200 & 125 & 113 & 0.800 & 80 \\
300 & 140 & 108 & 0.821 & 82.1 \\
400 & 162 & 96 & 0.846 & 84.6 \\
500 & 210 & 90 & 0.881 & 88.1 \\
600 & 261 & 80 & 0.904 & 90.4 \\
\hline
\end{tabular}
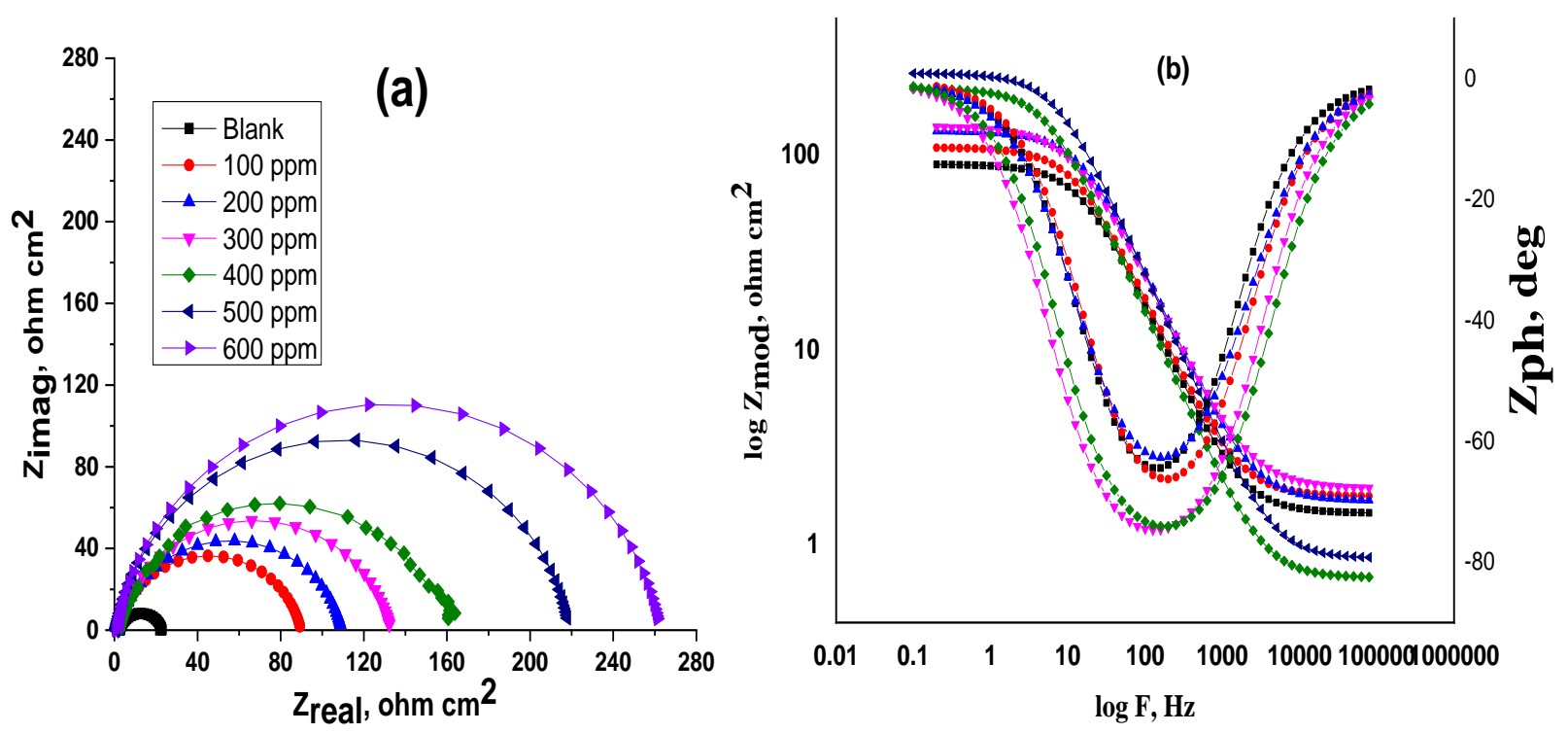

Figure 7. (a) Nyquist and (b) Bode diagrams for CS corrosion with and without various concentrations of Wihania somnifera at $25^{\circ} \mathrm{C}$.

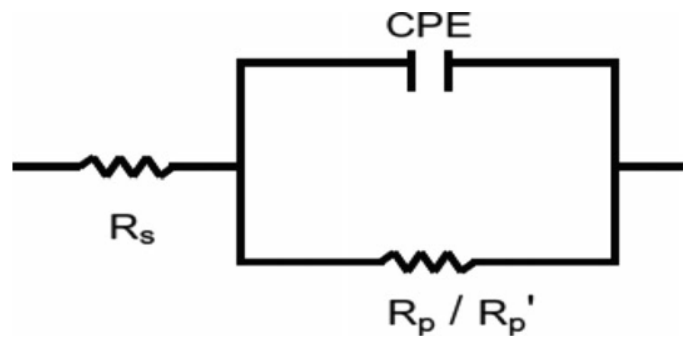

Figure 8. Equivalent model circuit recommended for fitting the EIS data. 


\section{AFM analysis}

The morphology of CS surface was analyzed using AFM experiments after immersion in $1 \mathrm{M} \mathrm{HCl}$ in the absence and the presence of $600 \mathrm{ppm}$ of Wihania somnifera extract for $24 \mathrm{~h}$, which affected the surface roughness. The mean roughness profile ( $\mathrm{Sa}$ ) values play an important role in identifying and reporting the efficiency of the inhibitor under study [29]. The roughness plays a role in the explanation of the nature of the adsorbed film on the surface. Figure 9a shows the clear CS surface which displays low roughness $(\mathrm{Sa}=21)$, Figure $9 \mathrm{~b}$ gives the surface of the metal damaged by $\mathrm{HCl}$ (blank) which displays a high roughness $(\mathrm{Sa}=612)$, and Figure $9 \mathrm{c}$ shows the CS surface exposed in the presence of $600 \mathrm{ppm}$ of Wihania somnifera extract which was not affected by corrosion and acquired the smallest roughness $(\mathrm{Sa}=173)$.
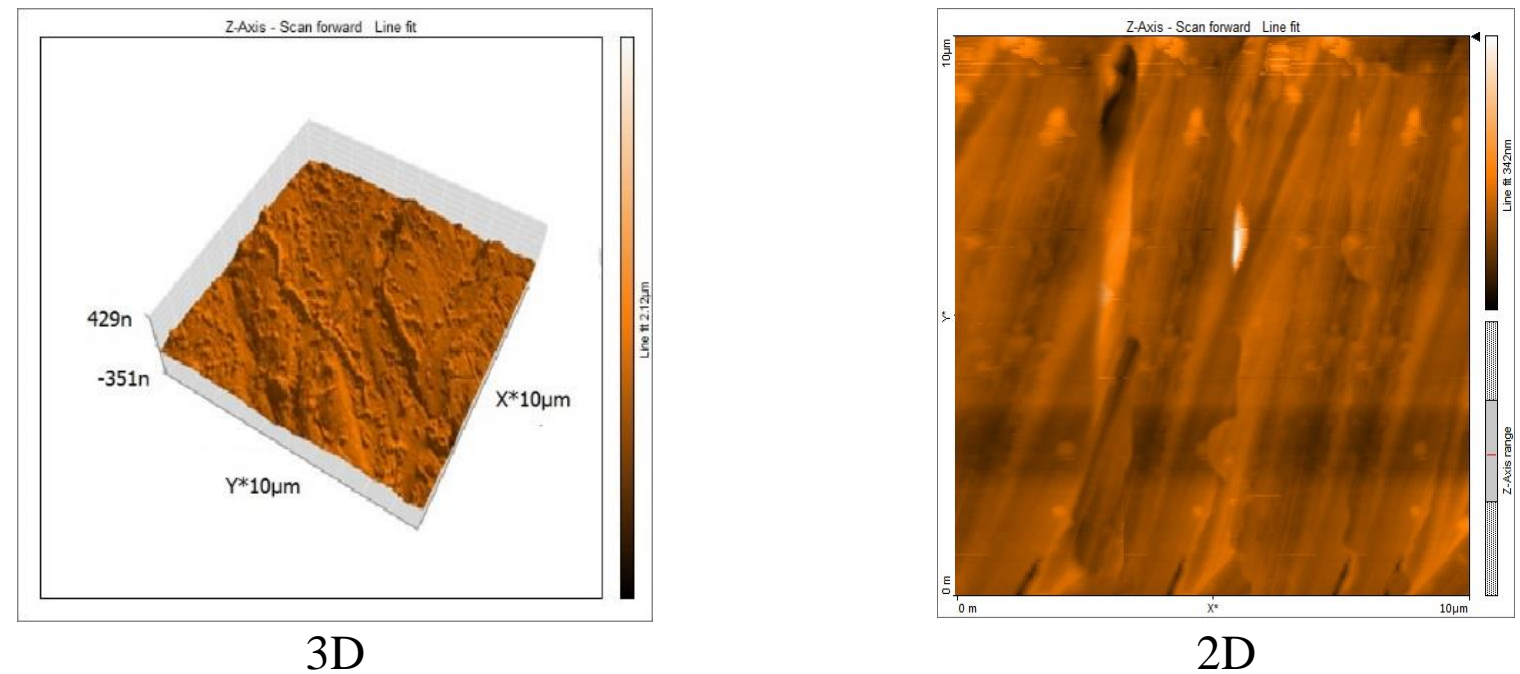

Figure 9a. (3D), (2D) AFM micrograph of CS before immersion in the acid.

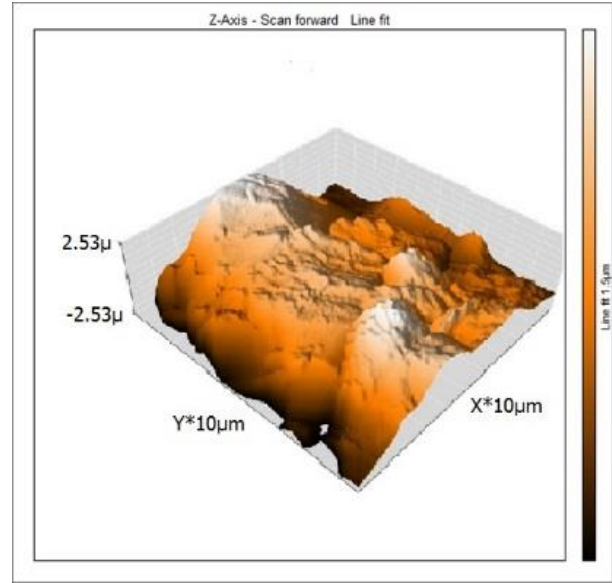

$3 \mathrm{D}$

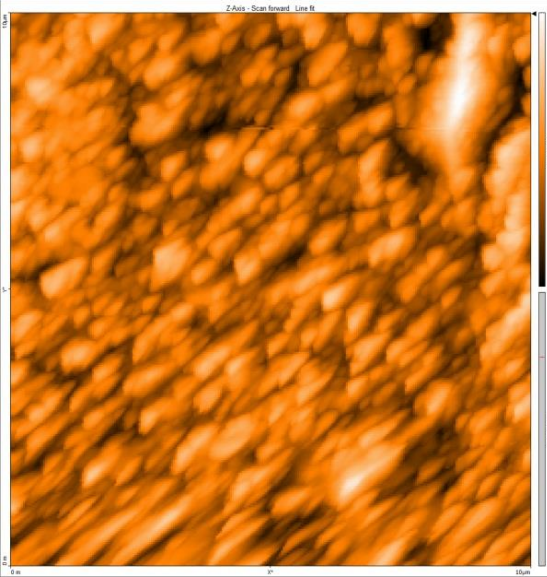

$2 \mathrm{D}$

Figure 9b. (3D), (2D) corroding surface of CS after immersion in the corrosive solution at $25^{\circ} \mathrm{C}$. 


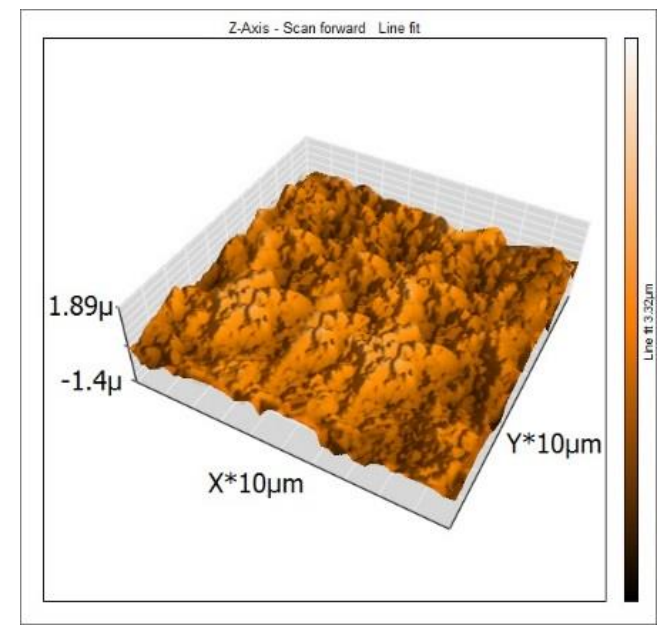

$3 \mathrm{D}$

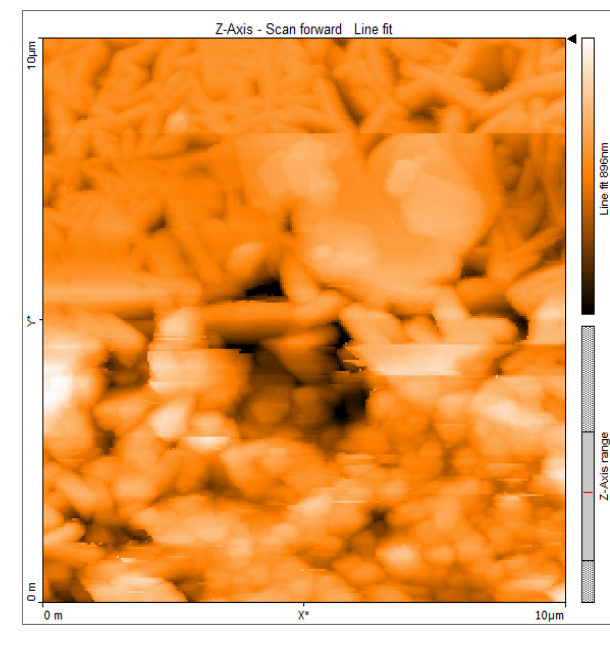

$2 \mathrm{D}$

Figure 9c. (3D), (2D) of inhibited carbon steel surface after immersion in the acid solution with 600 ppm of Wihania somnifera for 24 hours at $25^{\circ} \mathrm{C}$.

\section{Fourier Transform Infrared Spectra (FTIR) analysis}

FTIR is a powerful investigative tool to identify the functional groups in a molecule [32]. The FTIR spectrum of Wihania somnifera extract is revealed in Figure 10 to show a broad band at $3330 \mathrm{~cm}^{-1}$ due to the stretching vibrations of the $\mathrm{N}-\mathrm{H}$ bond. The band at $1636 \mathrm{~cm}^{-1}$ corresponds to the vibration of $\mathrm{C}=\mathrm{N}$, and that at $1157 \mathrm{~cm}^{-1}$ related to $v(\mathrm{C}-\mathrm{O})$ stretching bands under $1000 \mathrm{~cm}^{-1}$ corresponds to aliphatic and aromatic $(\mathrm{C}-\mathrm{H})$ groups. It is observed that there is a shift in the frequencies of the $\mathrm{N}-\mathrm{H}$ band from $3330 \mathrm{~cm}^{-1}$ to $3387 \mathrm{~cm}^{-1}$. This band that corresponds to the stretching vibrations of $\mathrm{C}=\mathrm{O}$ shifted from $1636 \mathrm{~cm}^{-1}$ to $1650 \mathrm{~cm}^{-1}$ while the band at $1057 \mathrm{~cm}^{-1}$ related to $v(\mathrm{C}-\mathrm{O})$ stretching vibrations shifted to $1174 \mathrm{~cm}^{-1}$.

\section{Explanation for corrosion inhibition mechanism}

This plant mainly contains anthraquinones, flavonoids, polyphenols, lipids, and sterols [30]. Since $E_{\text {corr }}$ in the presence of the extract increases compared to the value in its absence and the values of $\Delta G_{\text {ads }}^{0}$ are about $20 \mathrm{~kJ} \mathrm{~mol}^{-1}$, it follows that the extract molecules are adsorbed physically. In the acid medium the steel surface bears a positive charge, so the protonated extract molecules cannot approach the CS surface to adsorb on it due to electrostatic repulsion. The $\mathrm{Cl}^{-}$ions adsorbed on CS surface generate an extra negative charge near the solution and favor stronger adsorption of cations [31]. Owing to the lone electron pairs, the $\mathrm{O}$ and $\mathrm{N}$ atoms in Wihania somnifera molecules or the protonated molecules may bind with freshly produced $\mathrm{Fe}^{2+}$ ions on the CS surface to form CS-inhibitor complexes. These complexes are adsorbed onto the CS by Van der Waals forces to form a protective cover preventing carbon steel from corrosion. 


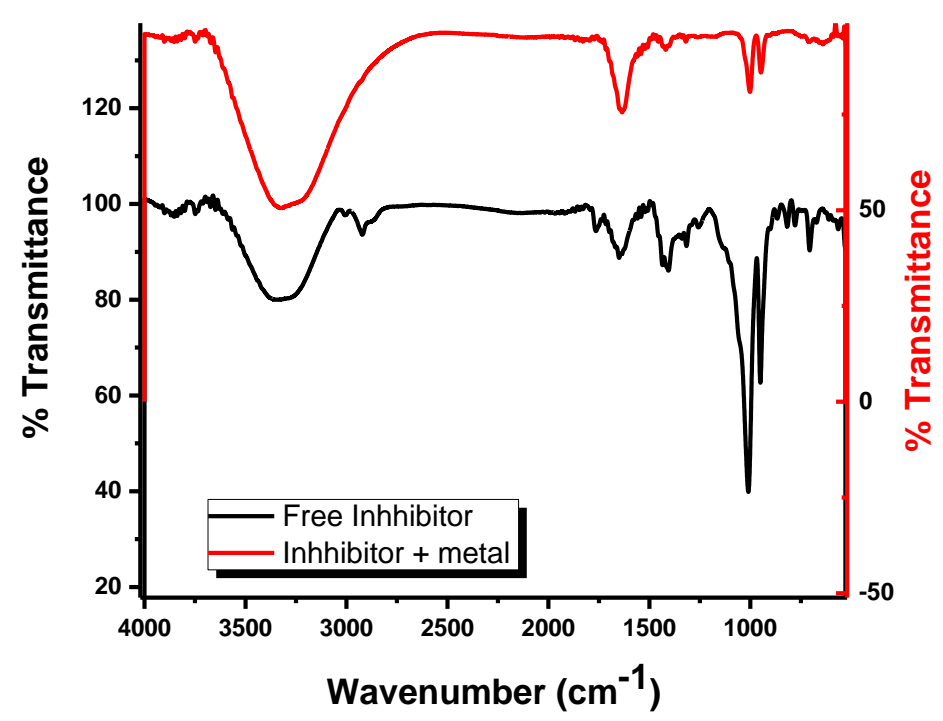

Figure 10. FTIR spectrum of Wihania somnifera before and after adsorption on the surface of $\mathrm{CS}$ at $25^{\circ} \mathrm{C}$.

\section{Conclusions}

The inhibition of the dissolution of CS in $1.0 \mathrm{M}$ hydrochloric solution by Wihania somnifera was determined by MR, PP, EIS and EFM measurements. Wihania somnifera can be used as an effective corrosion inhibitor for $\mathrm{CS}$ in $1 \mathrm{M} \mathrm{HCl}$ solution. The adsorption of Wihania somnifera was found to obey the Langmuir adsorption isotherm. The IE\% increases with an increase in the concentration of Wihania somnifera extract and decreases upon increase in the temperature of the medium. Wihania somnifera extract was adsorbed physically on CS surface. The PP data showed that Wihania somnifera extract acts as a mixed type inhibitor. The results obtained from electrochemical and non-electrochemical techniques are in excellent agreement.

\section{References}

1 M. Bouanis, M. Tourabi, A. Nyassi, A. Zarrouk, C. Jama and F. Bentiss, Corrosion inhibition performance of 2,5-bis (4-dimethylaminophenyl)-1,3,4-oxadiazole for carbon steel in $\mathrm{HCl}$ solution: Gravimetric, electrochemical and XPS studies, Appl. Surf. Sci., 2016, 89, no. 3, 952-966.

2. Y.G. Avdeev, Y.I. Kuznetsov and A.K. Buryak, Inhibition of steel corrosion by unsaturated aldehydes in solutions of mineral acids, Corros. Sci., 2013, 69, 50-60.

3. G. Ayyannan, K. Karthikeyan, S.S. Vivekananthan, M. Gopiraman and A. Rathinavelu, Chemical and electrochemical investigations of high carbon steel corrosion inhibition in $10 \% \mathrm{HCl}$ medium by quinoline chalcones, Ionics (Kiel), 2013, 19, 919-932.

4. V.V. Dhayabaran, I.S. Lydia, J.P. Merlin and P. Srirenganayaki, Inhibition of corrosion of commercial mild steel in presence of tetrazole derivatives in acid medium, Ionics (Kiel), 2004, 10, 123-125. 
5. M. Finšgar and J. Jackson, Application of corrosion inhibitors for steels in acidicmedia for the oil and gas industry: A review, Corros. Sci., 2014, 86, 17-41.

6. L.O. Olasunkanmi, I.B. Obot, M.M. Kabanda and E.E. Ebenso, Some quinoxalin-6-yl derivatives as corrosion inhibitors for mild steel in hydrochloric acid: Experimental and theoretical studies, J. Phys. Chem. C., 2015, 119, 16004-16019.

7. A. Saady, F. El-Hajjaji, M. Taleb, K. Ismaily Alaoui, A. El Biache, A. Mahfoud, G. Alhouari, B. Hammouti, D.S. Chauhan and M.A. Quraishi, Experimental and theoretical tools for corrosion inhibition study of mild steel in aqueous hydrochloric acid solution by new indanones derivatives, Mater. Discov., 2018, 12, 30-42.

8. A.S. Abousalem, M.A. Ismail and A.S. Fouda, A complementary experimental and in silico studies on the action of fluorophenyl-2,2'-bichalcophenes as ecofriendly corrosion inhibitors and biocide agents, J. Mol. Liq., 2019, 276, 255-274.

9. R.W. Bosch, J. Hubrecht, W.F. Bogaerts and B.C. Syrett, Electrochemical frequency modulation: a new electrochemical technique for online corrosion monitoring, Corrosion, 2001, 57, no. 1, 60-70. doi:10.5006/1.3290331

10. D.Q. Zhang, Q.R. Cai, X.M. He, 1.X. Gao and G.S. Kim, The inhibiting effect of Rumex vesicarius $L$. extract on the carbon steel corrosion in. $\mathrm{H}_{2} \mathrm{SO}_{4}$ was studied by weight loss, Mater. Chem. Phys., 2013, 114, no. 2-3, 612-617. doi: 10.1016/j.matchemphys.2008. $\underline{10.007}$

11. M.M. Saleh and A.A. Atia, Effects of structure of the ionic head of cationic surfactant on its inhibition of acid corrosion of mild steel, J. Appl. Electrochem., 2006, 36, no. 8, 899-905. doi: 10.1007/s10800-006-9147-6

12. J.O. Bockris and D.A.J. Swinkels, Adsorption of $n$-Decylamine on solid metal electrodes, J Electrochem. Soc., 1964, 111, no. 6, 736-748. doi: 10.1149/1.2426222

13. E. Khamis, The effect of temperature on the acidic dissolution of steel in the presence of inhibitors, Corrosion (NACE), 1990, 46, 476-484.

14. A. Popova, E. Sokolova, S. Raicheva and M. Christov, AC and DC study of the temperature effect on mild steel corrosion in acid media in the presence of benzimidazole derivatives, Corros Sci., 2003, 45, 33-58. doi: 10.1016/S0010-938X(02)00072-0

15. E. M.Sherif and S. M.Park, Inhibition of copper corrosion in acidic pickling solutions by Nphenyl-1,4-phenylenediamine, Electrochim. Acta, 2006, 51, no. 22, 4665-4673. doi: 10.1016/j.electacta.2006.01.007

16. I.Putilova and S.B. Barannik, Pergamon press, Metallic Corrosion Inhibitors, New York, 1960, 31-37.

17. A.S. Fouda, K. Shalabi, A.M. Nofal and M.A. EL-Zekred, Methanol extract of Rumex Vesicarius L. as eco-friendly corrosion inhibitor for carbon steel in sulfuric acid solution, Chem. Sci. Trans., 2018, 7, no. 1, 101-111.

18. F. Bentiss, M. Traisnet and M. Lagrenee, The substituted 1,3,4-oxadiazoles: a new class of corrosion inhibitors of mild steel in acidic media, Corros. Sci., 2000, 42, no. 1, $127-$ 136. doi: $10.1016 / \mathrm{S} 0010-938 X(99) 00049-9$ 
19. K.M. Hany, A. Abd El-Lateef, K. H.Soliman and A. Tantawy, Novel synthesized Schiff Base-based cationic gemini surfactants: Electrochemical investigation, theoretical modeling and applicability as biodegradable inhibitors for mild steel against acidic corrosion, J. Mol. Liq., 2017, 232, 478-498.

20. A.S. Fouda, K. Shalabi, El-Hossiany, A. Moxifloxacin, Antibiotic as green corrosion inhibitor for carbon steel in $1 \mathrm{M} \mathrm{HCl}, \mathrm{J}$. Bio- and Tribo- Corros., 2016, 2, no. 18, 1-13.

21. A.S. Abousalem, M.A. Ismail and A.S. Fouda, A complementary experimental and in silico studies on the action of fluorophenyl-2,2'-bichalcophenes as ecofriendly corrosion inhibitors and biocide agents, J. Mol. Liq., 2019, 276, 255-274.

22. A.S. Fouda, A. El-Hossiany and H. Ramadan, Calotropis procera plant extract as green corrosion inhibitor for 304 stainless steel in hydrochloric acid solution, IJRASET, 2017, 5, 541-555.

23. M.M. Saleh, M.G. Mahmoud and H.M. Abd El-Lateef, Comparative study of synergistic inhibition of mild steel and pure iron by 1-hexadecylpyridinium chloride and bromide ions, Corros. Sci., 2019, 154, 70-79.

24. A.S. Fouda, M.A. Abd El-Ghaffar, M.H. Sherif, A. Taher El-Habab, A. El-Hossiany, Novel anionic 4-tert-octyl phenol ethoxylate phosphate surfactant as corrosion inhibitor for C-steel in acidic media, Prot. Met. Phys. Chem. Surf., 2020, 56, no. 1, 189-201.

25. A.S. Fouda, M. Abdel Azeem, S.A. Mohamed, A. El-Hossiany and E. El-Desouky, Corrosion inhibition and adsorption behavior of nerium oleander extract on carbon steel in hydrochloric acid solution, Int. J. Electrochem. Sci., 2019, 14, 3932-3948.

26. S.H. Kumar and S. Karthikeyan, Inhibition of mild steel corrosion in hydrochloric acid solution by cloxacillin drug, J. Mater. Environ. Sci., 2012, 3, no. 5, 925-934.

27. M.M. Motawea, A. El-Hossiany and A.S. Fouda, Corrosion control of copper in nitric acid solution using Chenopodium extract, Int. J. Electrochem. Sci., 2019, 14, 1372-1387.

28 A.S. Fouda, H. Ibrahim, S. Rashwan, A. El-Hossiany and R.M. Ahmed, Expired drug (pantoprazole sodium) as a corrosion inhibitor for high carbon steel in hydrochloric acid solution, Int. J. Electrochem. Sci., 2018, 13, 6327-6346.

29. A.S. Fouda, M. Eissa and A. El-Hossiany, Ciprofloxacin as eco-friendly corrosion inhibitor for carbon steel in hydrochloric acid solution, Int. J. Electrochem. Sci., 2018, 13, 11096-11112.

30. R.W. Bosch, J. Hubrecht, W.F. Bogaerts and B.C. Syrett, Electrochemical frequency modulation: A new electrochemical technique for online corrosion monitoring, Corrosion, 2001, 57, no. 1, 60-70.

31. D.Q. Zhang, Q.R. Cai, X.M. He, I.X. Gao and G.S. Kim, Corrosion inhibition and adsorption behavior of methionine on copper in $\mathrm{HCl}$ and synergistic effect of zinc ions, Mater. Chem. Phys., 2013, 114, 612-617. 